insulin resistance is also supported by reported associations of the INS VNTR class III allele with a number of conditions in which insulin resistance is a major feature $^{2,3}$, such as polycystic ovary syndrome and central obesity. Thus, selective peripheral insulin resistance could explain the III/III genotype associations with both larger size at birth and insulin resistance or type 2 diabetes risk. Similarly, in conditions of fetal growth restraint, such as poor nutrition in pregnancy, peripheral insulin resistance may also represent a fetal metabolic adaptation that diverts nutrients to protect brain and skeletal growth in utero ${ }^{12}$, but may lead to disease in adulthood.
Ken K.L. Ong ${ }^{1}$, David I. Phillips²,

Caroline Fall' ${ }^{2}$, Jo Poulton ${ }^{1}$, Simon T. Bennett ${ }^{3}$, Jean Golding ${ }^{4}$, John A. Todd ${ }^{5}$ \& David B. Dunger ${ }^{1}$ Department of Paediatrics, University of Oxford, John Radcliffe Hospital, Oxford OX3 9DU, UK. ${ }^{2} M R C$ Unit, University of Southampton, Southampton General Hospital, Southampton SO16 6YD, UK. ${ }^{3}$ Oxagen Ltd, 91 Milton Park, Abingdon, OX14 $4 R Y, U K .{ }^{4}$ Unit of Paediatric \& Perinatal Epidemiology, University of Bristol, 24 Tyndall Avenue, Bristol BS8 1TQ, UK. ${ }^{5}$ Department of Medical Genetics, Cambridge Institute for Medical Research, University of Cambridge, Wellcome Trust/MRC Building, Hills Road, Cambridge CB2 2XY, UK. Correspondence should be addressed to J.A.T. (e-mail: john.todd@cimr.cam.ac.uk) or D.B.D. (e-mail: david.dunger@paediatrics.oxford.ac.uk).

1. Dunger, D.B. et al. Nature Genet. 19, 98-100 (1998) 2. Bennett, S.T. \& Todd, J.A. Annu. Rev. Genet. 30, 343-370 (1996)

3. Waterworth, D.M. et al. Lancet 349, 986-990 (1997) 4. McCarthy, M. Nature Genet. 19, 209-210 (1998).

5. Hales, C.N. et al. Br. Med. J. 303, 1019-1022 (1991)

6. Phillips, D.I. Diabetologia 39, 1119-1122 (1996).

7. Bennett, S.T. et al. J. Autoimmun. 9, 415-421 (1996).

8. Vafiadis, P. et al. J. Autoimmun. 9, 397-403 (1996).

9. Paquette, J., Giannoukakis, N., Polychronakos, C., Vafiadis, P. \& Deal, C. J. Biol. Chem. 273 14158-14164 (1998)

10. Jensen, M.D., Miles, J.M., Gerich, J.E., Cryer, P.E. \& Haymond, M.W. Am. J. Physiol. 254, E700-707 (1988). 11. Amiel, S.A. et al. J. Clin. Endocrinol. Metab. 72 277-282 (1991)

12. Simmons, R.A., Flozak, A.S. \& Ogata, E.S. Endocrinology 133, 1361-1368 (1993).

13. Julier, C. et al. Am. J. Hum. Genet. 55, 1247-1254 (1994)

\title{
Deafness linked to DFNA2: one locus but how many genes?
}

$\mathrm{H}^{2}$ ereditary hearing impairment shows extreme genetic heterogeneity and more than 40 different loci have been reported. One of these, DFNA2, was localized to chromosome 1p34 on the basis of ing loss originating from Indonesia and the United States ${ }^{1}$. Subsequently, hearing loss in three additional large families from Belgium and the Netherlands was found to map to the same region ${ }^{2}$.

Two different genes are now reported to be the 'DFNA2' gene. In December's issue of Nature Genetics, Jia-Hui Xia and colleagues described two small Chinese families with nonsyndromic autosomal dominant hearing loss in which they tion in GJB3, which encodes connexin 31 (ref. 3). As GJB3 is located on chromosome 1p34, it was proposed, in an accompanying News \& Views that GJB3 is a good candidate for involvement in DFNA2 families $^{4}$. Extensive sequence analysis of the coding region and the 5' UTR of GJB3 in linkage analysis in two large families with autosomal dominant nonsyndromic hearfound a missense and a nonsense muta-

all 5 DFNA2 families revealed no mutations, however (data not shown). A recent report in Cell reports the identification of a novel member (KCNQ4) of the potassium channel family KCNQ, also located on chromosome 1p34. Its authors found its mutation to segregate with hearing loss in a small French family, and claimed the identification of the DFNA2 gene.

Which one of these claims is correct? An obvious point to consider is that DFNA2 (Fig. 1) is the name of a chromosomal locus identified by linkage analysis, rather than a gene. Our analysis indicates that the candidate region delineated by the Indonesian family does not overlap with the candidate region of one of the Dutch families. The candidate regions of the remaining families overlap with both candidate regions (Fig. 1). KCNQ4 is located in the candidate region of four families (Fig. 1); it is therefore possible that KCNQ4 is responsible for hearing loss in these 'DFNA2' families, but conclusive data awaits mutation analysis. The centromeric recombinant of the Indonesian family excludes this gene as a

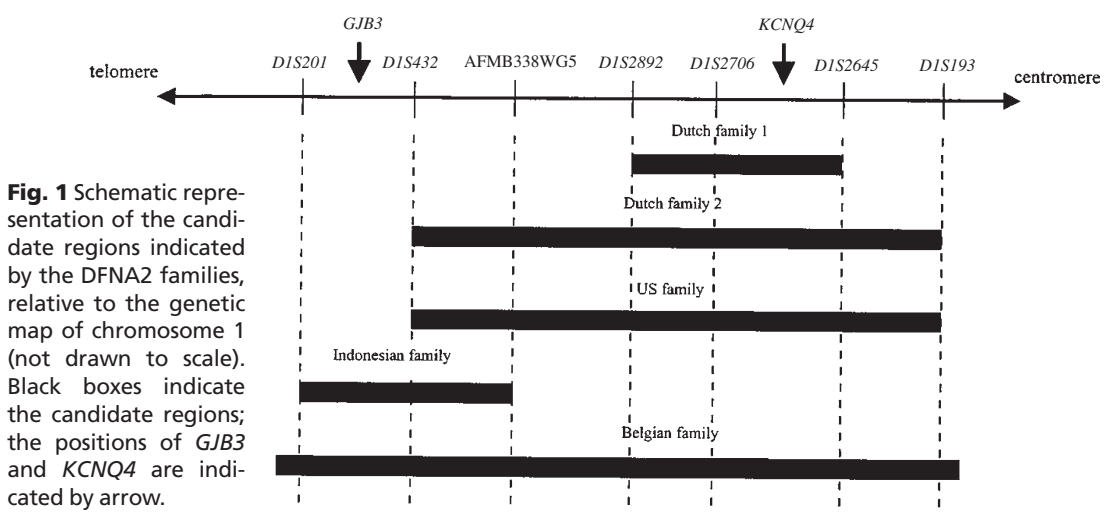

possible candidate gene for hearing loss in this family, suggesting the presence of a third deafness gene in this region.

As both GJB3 and KCNQ4 are responsible for nonsyndromic autosomal dominant hearing loss and are present in the DFNA2 region, each of them can be considered to be a 'DFNA2' gene (a hearing loss gene from the DFNA2 region), rather than the 'DFNA2' gene. As nonsyndromic deafness is a paradigm of genetic heterogeneity ${ }^{6}$, the presence of different genes responsible for nonsyndromic deafness in a small chromosomal region is not all that surprising. This situation may not be limited to hearing loss, as two different genes have been suggested at one locus for retinitis pigmentosa $a^{7,8}$, another prime example of genetic heterogeneity. The question posed in our title is therefore legitimate, and DFNA2 may not be the only locus to which it applies.

Peter Van Hauwe1, Paul J. Coucke ${ }^{1}$, Frank Declau ${ }^{2}$, Henricus Kunst ${ }^{3}$, Robbert J. Ensink ${ }^{3}$, Henri A. Marres ${ }^{3}$, Cor W.R.J. Cremers 3 ,

Bulantrisna Djelantik ${ }^{4}$, Shelley D. Smith ${ }^{5}$, Phil Kelley ${ }^{5}$, Paul H. Van de Heyning ${ }^{2}$ \& Guy Van Camp ${ }^{1}$

${ }^{1}$ Department of Medical Genetics and

2Otolaryngology, University of Antwerp, Universiteitsplein 1, B2610 Antwerp, Belgium.

${ }^{3}$ Department of Otolaryngology, University Hospital, NL-6500 Nijmegen, The Netherlands. ${ }^{4}$ Department of Otolaryngology, Padjadjaran University Medical School, 40161 Bandung, Indonesia. ${ }^{5}$ Center for Hereditary

Communication Disorders, Boys Town National Research Hospital, 555 North $30^{\text {th }}$ Street,

Omaha, Nebraska 68131, USA. Correspondence should be addressed to G.V.C. (e-mail: gvcamp@uia.ua.ac.be)

1. Coucke, P. et al. N. Engl. J. Med. 331, 425-431 (1994).

2. Van Camp, G. et al. Genomics 41, 70-74 (1997).

3. Xia, J.H. et al. Nature Genet. 20, 370-373 (1998)

4. Steel, K.P. Nature Genet. 20, 319-320 (1998).

5. Kubisch, C. et al. Cell 96, 437-446 (1999).

6. Van Camp, G., Willems, P.J. \& Smith, R.J. Am. J. Hum. Genet. 60, 758-764 (1997).

7. Meindl, A. et al. Nature Genet. 13, 35-42 (1996)

8. Souied, E., Kaplan, J., Soubrane, G. \& Coscas, G. J. Fr. Ophthalmol. 20, 461-486 (1997). 